\title{
Crenças de estudantes do ensino médio do IFRN/ Campus Pau dos Ferros sobre o internetês
}

Luan Talles de Araújo Brito ${ }^{1}$ Auiã Tobias Chaves Coelho ${ }^{2}$ Mirla Isabel Lopes Gomes ${ }^{3}$ Yasmim Mendes da Costa ${ }^{4}$

\begin{abstract}
Resumo:
Este artigo advém de um projeto de pesquisa desenvolvido no IFRN/Campus Pau dos Ferros, cujo objeto de estudo foram as crenças de estudantes do ensino médio sobre o internetês. Os objetivos do trabalho são: entender as crenças dos referidos discentes sobre o internetês e refletir sobre as possivivis origens dessas crenças. O corpus foi formado a partir da aplicação remota de um questionário misto. No referencial teórico, destacam-se as contribuições de Barcelos (2001), Silva (2007), Rocha (2010), Brito (2019), Bisognin (2009), Gonzalez (2007) e Xavier (2014). Os resultados revelam que a maioria dos estudantes acredita na facilidade de leitura do internetês, considerando-o ora um vício de linguagem a ser evitado, ora um reflexo do fenômeno de variação linguística o qual não prejudica a aprendizagem formal. Além disso, verificou-se que a maior parte dos informantes não recebeu instruções em sala de aula acerca do uso adequado do internetês, o que evidencia a necessidade de a escola oportunizar cada vez mais espaços de discussão sobre os usos contemporâneos da linguagem.
\end{abstract}

\section{Palavras-chave:}

Crenças. Estudantes. Ensino Médio. Internetês.

\section{Beliefs of high school students from IFRN/ Campus Pau dos Ferros about the netlingo}

\footnotetext{
Abstract: This article comes from a research project developed at the IFRN/Campus Pau dos Ferros, whose object of study were the beliefs of high school students about the netlingo. The objectives of the study are: to understand the beliefs of the students about the netlingo and to reflect on the possible origins of these beliefs. The corpus was formed from the remote application of a mixed questionnaire. In the

1 Doutor em Letras, Professor de Língua Portuguesa e Literatura, no IFRN Campus Pau dos Ferros. E-mail: luantalles_tdb@hotmail.com. ORCID iD: https://orcid.org/0000-0003-1425-4936.

2 Estudante do 2ㅇ ano do Curso Técnico Integrado em Apicultura, do IFRN Campus Pau dos Ferros. E-mail: tobias.auia@academico.ifrn.edu.br.

3 Estudante do 2 o ano do Curso Técnico Integrado em Informática, do IFRN Campus Pau dos Ferros. E-mail: mirla.lopes@academico.ifrn.edu.br.

4 Estudante do 2ㅇ ano do Curso Técnico Integrado em Informática, do IFRN Campus Pau dos Ferros. E-mail: yasmim.mendes@academico.ifrn.edu.br.
} 
theoretical framework, the contributions of Barcelos (2001), Silva (2007), Rocha (2010), Brito (2019), Bisognin (2009), Gonzalez (2007) and Xavier (2014), among others. The results show that the majority of students believe in the ease of reading the netlingo, considering it a language addiction to avoid, but also a reflection of the phenomenon of linguistic variation which does not harm formal learning. In addition, it was found that most of the informants did not receive instructions in the classroom about the proper use of the netlingo, which shows the need for the school to provide more spaces for discussion about contemporary uses of language.

Keywords: Beliefs. Students. High school. Netlingo.

\section{Creencias de estudiantes de la enseñanza media del IFRN/ Campus Pau dos Ferros a respecto del internetês}

Resumen: Este artículo viene de un proyecto de investigación desarrollado en IFRN/Campus Pau dos Ferros, cuyo objeto de estudio fueron las creencias de estudiantes de la enseñanza media a respecto del internetês. Los objetivos del trabajo son: comprender las creencias de los aprendices mencionados sobre el internetês y reflexionar a respecto de los posibles orígenes de esas creencias. El corpus fue hecho a partir de la aplicación en línea de un cuestionario mixto. En la base teórica, se destacan las contribuciones de Barcelos (2001), Silva (2007), Rocha (2010), Brito (2019), Bisognin (2009), Gonzalez (2007) y Xavier (2014). Los resultados revelan que la mayoría de los estudiantes creen en la facilidad de lectura del internetês, considerándolo como un vicio de lenguaje a ser evitado y como un reflejo del fenómeno de la variación lingüística el cual no impide el aprendizaje formal. Además, se verificó que la mayor parte de los respondientes no recibió instrucciones en el aula sobre el uso adecuado del internetês, lo que evidencia la necesidad de la escuela propiciar cada vez más espacios de discusión acerca de los usos diversos y contemporáneos del lenguaje.

Palabras-clave: Creencias. Estudiantes. Enseñanza media. Internetês.

\section{Introdução}

A escrita é muito importante na comunicação humana. Ela está presente no nosso cotidiano através dos textos que usamos com diferentes finalidades e situações comunicativas, seja através de um bilhete, carta pessoal, outdoor, notícia impressa ou eletrônica, Facebook, WhatsApp, etc. Sendo assim, é perceptível o papel de destaque que a modalidade escrita da língua assume atualmente no processo de interlocução de um número significativo de comunidades linguísticas.

Por seu turno, o surgimento de novos gêneros textuais e a consequente diversidade de modelos comunicativos repercutem não apenas em benefícios, mas também em preocupações no tocante à formação de adolescentes e de jovens, por estarem em um momento de amadurecimento e de construção de valores que os nortearão ao longo de suas vidas.

É mister que os estudantes se conscientizem sobre a importância do uso adequado do dialeto escrito (BISOGNIN, 2009; XAVIER, 2014) popularizado na internet: o internetês. Isso nos motivou a investigar as crenças de estudantes acerca desse fenômeno linguístico, oportunizando assim um espaço de discussão que reflita sobre aspectos da produção textual escrita dos alunos do Curso Técnico Integrado em Informática ${ }^{1}$, do Campus Pau dos Ferros - IFRN, fornecendo subsídios para um processo de conscientização da variação e adequação linguísticas.

1 Ressaltamos que a escolha desse público alvo (estudantes do Curso Técnico Integrado em Informática) levou em consideração critérios estabelecidos no edital em que nosso projeto de pesquisa foi aprovado, que estabelecia a necessidade de a temática do projeto relacionar-se ao eixo técnico dos cursos ofertados no campus de execução. 
A relevância dessa pesquisa reside no fato de que a investigação das crenças de alunos sobre o internetês favorece o debate acerca das características e do uso de uma escrita que se faz presente no cotidiano de muitos jovens (e até mesmo adultos), principalmente na comunicação informal estabelecida em redes sociais e aplicativos de bate-papo. Além disso, pesquisas já constataram que alguns estudantes acabam empregando o internetês em textos escolares formais (SANCHES, 2013; BRITO, 2013, 2015), o que preocupa haja vista a necessidade de adequação do uso da linguagem à formalidade/informalidade da situação comunicativa de que o sujeito participa.

Nesse sentido, a investigação das crenças de alunos do Curso Técnico Integrado em Informática, do Campus Pau dos Ferros - IFRN, favorece a reflexão sobre a postura de consciência desses sujeitos quanto à necessidade de monitoramento de sua escrita e de adequação linguística, além de possibilitar a análise científica das características e da maneira como os estudantes se posicionam ante o emprego dessa variedade linguística (ÁVILA; COX, 2008).

\section{Metodologia}

Este artigo é resultado de um projeto de pesquisa desenvolvido no Campus Pau dos Ferros, do Instituto Federal de Educação, Ciência e Tecnologia do Rio Grande do Norte (IFRN). O projeto foi aprovado no Edital no 04/2020 - PROPI/RE/IFRN, sendo executado de 04 de setembro de 2020 a 04 de abril de 2021. Para uma melhor compreensão dos resultados aqui discutidos, iremos expor brevemente neste tópico como se deu o percurso trilhado no projeto, a coleta de dados, bem como a análise destes.

Na primeira etapa (de 04 de setembro a 16 de outubro de 2020), a equipe reuniu-se remotamente, por meio do Microsoft Teams e do Google Meet, para estudar e debater textos teóricos, pesquisas, bem como artigos científicos já publicados pelo coordenador do projeto, relacionados à discussão de crenças de alunos e sobre o internetês. Neste período, os alunos (bolsista e voluntários) produziram resumos, fichas de leitura e paráfrases.

$\mathrm{Na}$ etapa seguinte, a equipe discutiu as características e o uso de questionários em pesquisas científicas, especialmente nos estudos de crenças, da Linguística Aplicada, bem como produziu coletivamente um questionário usando a ferramenta digital Google Forms ${ }^{2}$. De 07 de novembro a 03 de dezembro de 2020, o questionário foi aplicado junto aos informantes, seja por meio de seu compartilhamento nos grupos de WhatsApp das turmas de 1, 2o, 3o e 4o ano do Curso Técnico Integrado em Informática, do IFRN/Campus Pau dos Ferros, seja pelo seu envio por e-mail.

Quanto aos procedimentos de coleta de dados, a pesquisa proposta neste projeto caracteriza-se como estudo de campo, uma vez que este "focaliza uma comunidade, que não é necessariamente geográfica, já que pode ser uma comunidade de trabalho, de estudo, de lazer ou voltada para qualquer outra atividade humana" (GIL, 2002, p. 53). Neste caso, ressaltamos que o questionário foi aplicado em sete (07) turmas, já que, no IFRN/Campus Pau dos Ferros, no período de coleta de dados supracitado, existiam turmas de 1o, 2 e e 3 o ano nos turnos matutino e vespertino. Em contrapartida, existia apenas uma (01) turma de 4o ano, no turno matutino.

Vale ressaltar que optamos pela aplicação do questionário on-line devido ao formato educacional então adotado pelo IFRN em todos os seus campi, que foi o ensino remoto emergencial, tendo em vista o cenário de pandemia do coronavírus. Desse modo, a produção e aplicação do questionário on-line foi a estratégia de coleta de dados mais viável nesse contexto. Apesar de a equipe do projeto ter compartilhado o questionário nos grupos de WhatsApp das turmas algumas vezes, bem como ter solicitado o apoio de líderes de turma e de professores que lecionavam para o público alvo da pesquisa, o número total de respondentes foi de apenas 48 estudantes.

2 Para fins de comprovação, o link de acesso ao questionário é o seguinte: https://forms.gle/kpgcsvt6bqShLdGdA. No entanto, ressaltamos que o formulário não está mais recebendo respostas. 
Ao longo do artigo, quando necessário, serão utilizados os nomes fornecidos pelos participantes no questionário, os quais foram informados da opção de se identificar com um nome fictício ou com seu nome real. Ao final do questionário, os estudantes responderam a um termo de consentimento de uso dos dados cedidos para fins de pesquisa.

Após a aplicação dos questionários, a equipe se reuniu remotamente para selecionar, discutir e organizar os dados quantitativamente e qualitativamente, relacionando-os ao que havia sido discutido teoricamente na primeira etapa do projeto. A partir disso, este artigo foi produzido por três (03) estudantes de ensino médio que integravam a equipe do projeto de pesquisa e pelo professor coordenador do projeto. Nessa perspectiva, a análise dos dados será realizada comparativamente, levando em conta semelhanças e diferenças entre as informações dos estudantes das quatro séries investigadas.

\section{Revisão bibliográfica}

Para uma melhor compreensão e análise do objeto de estudo proposto neste artigo, faz-se necessária a discussão do conceito de crenças, conforme os estudos do campo da Linguística Aplicada, bem como a abordagem das características e usos do internetês.

\section{O conceito de crenças na Linguística Aplicada}

A pesquisa acerca de crenças e de seu impacto no processo de ensino-aprendizagem de línguas tem despertado cada vez mais a atenção de estudiosos, seja no cenário científico do exterior, seja no do Brasil. As investigações sobre a temática tiveram início entre as décadas de 70 e 80 , no âmbito internacional, e na década de 90, no âmbito nacional. Para Barcelos (2004), o interesse pelo estudo das crenças originou-se de uma mudança de paradigma na Linguística Aplicada, em que o foco na discussão em torno da educação linguística passou a ser não mais a linguagem em si, mas os sujeitos envolvidos no processo de ensino-aprendizagem: professor e aprendiz.

No que tange à definição, consoante Silva (2007), as crenças, nas pesquisas empreendidas na área da Linguística Aplicada, não estão relacionadas à religião ou superstição. Apesar de não haver uma uniformidade na definição do que são crenças, em uma perspectiva geral, "elas podem ser definidas como opinióes e ideias que alunos (e professores) têm a respeito dos processos de ensino e aprendizagem de línguas" (BARCELOS, 2001, p. 72, grifos nossos).

Assumindo o posicionamento de que não existe uma definição unívoca deste construto na sua aplicação e investigação sobre o ensinar e o aprender linguístico, Silva (2005, p. 77, grifos nossos) define-o de modo semelhante a Barcelos (2001):

Ideias ou conjunto de ideias para as quais apresentamos graus distintos de adesão (conjecturas, ideias relativamente estáveis, convicção e fé). As crenças na teoria de ensino e aprendizagem de línguas são essas ideias que tanto alunos, professores e terceiros têm a respeito dos processos de ensino/aprendizagem de línguas e que se (re)constroem neles mediante as suas próprias experiências de vida e que se mantêm por um certo período de tempo.

É possível notar, portanto, o destaque dado por esse autor para o caráter contextual, interativo e relativamente estável das crenças ao afirmar que elas são emergentes, isto é, construídas e reconstruídas nos processos de ensino-aprendizagem, influenciando e sendo influenciadas reciprocamente por tais processos, uma vez que são também "vistas como social e, portanto, também cultural e historicamente constituídas através da interação do sujeito com o contexto" 
(SILVA, 2007, p. 250). No que lhe diz respeito, Barcelos (2006) aprofunda a sua compreensão acerca dessa categoria analítica e assume uma postura convergente com o pensamento de Silva (2007), compreendendo crenças como:

uma forma de pensamento, como construções da realidade, maneiras de ver e perceber o mundo e seus fenômenos, co-construídas em nossas experiências e resultantes de um processo interativo de interpretação e (re)significação. Como tal, crenças são sociais (mas também individuais), dinâmicas, contextuais e paradoxais. (BARCELOS, 2006, p. 18, grifos nossos).

Nessa perspectiva, vemos como a autora considera o caráter histórico das crenças ao afirmar que elas são formadas ao longo das experiências e interações pelas quais os sujeitos passam ao longo de suas vidas. Soares (2005), convergindo com Barcelos (2006), auxilia a compreensão do caráter ambivalente das crenças e explica que as crenças são individuais porque cada pessoa é única e demonstra uma maneira própria de apreender experiências, interpretar o mundo e posicionar-se frente aos acontecimentos. Por seu turno, Ramos (1997) acrescenta que elas ultrapassam a dimensão do individual à medida que são também construídas e reconstruídas na coletividade, nas interações que o sujeito realiza com os demais membros do grupo ou da sociedade de que participa.

Dufva (2003) defende que as crenças se manifestam por meio das "práticas discursivas" realizadas nos diferentes grupos da sociedade. Porquanto, o outro, o nosso interlocutor assume grande importância na construção de nosso pensamento e na forma como percebemos o mundo à nossa volta, uma vez que pensamos, ativando e reativando nossas crenças, tendo em vista os sentidos que construímos a partir das interações com os nossos interlocutores, sejam eles reais ou presumidos (BAKHTIN, 2009). Desse modo,

as crenças, sob um viés bakhtiniano, podem ser conceituadas como os diferentes modos, axiologicamente (leia-se ideologicamente) constituídos, de se interpretar o mundo, refletindo-o e, também, refratando-o. São, portanto, maneiras discursiva e socioculturalmente situadas de se pensar, viver e sentir o mundo, das quais dialogicamente nos apropriamos ao participarmos dos infinitos modos em que se dão as relações humanas. Pelas crenças, expressamos nossas valorações ou juízos de valor, quando enunciamos. (ROCHA, 2010, p. 231-232, grifo nosso).

Neste caso, Rocha (2010) converge com Barcelos (2006) quando argumenta que as crenças são vistas como interpretações socioideológicas valorativas da realidade e seus fenômenos, situadas temporal e historicamente. Para a autora, elas se materializam nas inúmeras práticas discursivas de que os sujeitos participam ao longo da vida, através das quais manifestam princípios e juízos de valor. Isto posto, é importante frisar que:

além de dialogicamente (re)construídas [...] são também heteroglóssica e polifonicamente constituídas na e pela linguagem e, assim, impregnadas pela diversidade e pelos conflitos, assumindo um caráter polissêmico e dinâmico, em uma sociedade marcada, por sua vez, por contradições e confrontos de interesses e valores. (ROCHA, 2010, p. 232).

A partir desta definição e de toda a discussão traçada, torna-se necessário destacar que seguimos neste trabalho o conceito de crenças sistematizado por Brito (2019), o qual leva em conta os pressupostos de Barcelos (2006) e Rocha (2010). Nesse ponto de vista, entendemos as crenças de alunos como posições valorativas acerca de diferentes aspectos relacionados ao internetês e ao seu uso em textos escritos. Por sua vez, essas posições verbo-axiológicas são construídas e reconstruídas nas experiências pelas quais o sujeito passa ao longo da vida, sendo ainda influenciadas por diferentes fatores contextuais. 
Embora não sejam definidas como certas ou erradas, as crenças de alunos podem ser avaliadas como adequadas ou inadequadas no que diz respeito a determinadas teorias que contribuem para o entendimento do processo da variação linguística e do uso adequado da linguagem. Neste sentido, reiteramos que as crenças possuem dupla natureza, uma mais abstrata e outra mais empírica, já que, de um lado, manifestam-se discursivamente, e por outro, podem se materializar nas tomadas de decisões e ações executadas pelo discente em sua jornada estudantil.

\section{As características e os usos do internetês}

O internetês apresenta uma regularidade, pois

até na desorganização que aparenta ser, o léxico da linguagem dos internautas jovens não foge ao sistema, há um conjunto de regras repetidas mesmo sendo diferentes das seguidas na forma oficial, especialmente as que se referem à grafia. (BISOGNIN, 2009, p. 29).

Nessa perspectiva, Gonzalez (2007) e Moura e Pereira (2011) destacam em seus estudos as seguintes características dessa escrita: 1 - abreviação; 2 - substituição (troca de letras por outras ou troca de acentos gráficos por formas correspondentes); 3 - aspectos suprassegmentais (uso de letras maiúsculas e alongamento vocálico); 4 - aspectos paralinguísticos (uso dos emoticons ou caracteres).

No âmbito da Sociolinguística são discutidos diferentes tipos de variação linguística, um deles é a variação estilística, a qual se relaciona ao uso multifacetado da língua conforme o grau de formalidade ou informalidade da situação comunicativa. Conforme Brito (2015), em sua dissertação de mestrado, o internetês pertence ao domínio da variação estilística, já que se configura como uma adequação da modalidade escrita do português brasileiro, operada pelos internautas, em situações comunicativas notadamente informais. Por conseguinte,

Não há motivos para alardes, pois se trata apenas de uma utilização mais flexível dos grafemas do léxico em uma dada situação comunicativa e não de uma conspiração orquestrada contra a língua portuguesa para desestabilizar o léxico e a gramática como um todo. (XAVIER, 2014, p. 172).

Explicado o motivo para não se ter uma visão apocalíptica acerca do internetês, é necessário destacar que o uso adequado dessa variedade está relacionado, especificamente, aos gêneros informais da esfera virtual ou eletrônica de comunicação, sendo inadequada a transposição dessa escrita para os textos formais produzidos na esfera escolar ou em outros contextos comunicativos. Esses textos pertencem, geralmente, a esferas comunicativas que requerem o uso e o domínio da norma padrão da língua. Nesse caso, o fenômeno linguístico informal da comunicação eletrônica perde a

sua função 'bacana', de identificação de grupo, quando são retiradas da tecnologia, seja o telefone celular ou o computador. O fato de que alguns garotos possam começar a usar abreviações em lugares onde elas não têm qualquer propósito - como em redações escolares - deve ser vigiado, naturalmente. (CRYSTAL, 2005, p. 92).

Portanto, essa "vigilância" perpassa o desenvolvimento da competência comunicativa do aluno, a partir da qual ele poderá interagir de modo responsável, adequando os seus enunciados à situação comunicativa. Sendo assim, a pesquisa de crenças de alunos sobre o internetês possibilita até mesmo analisar se, de fato, esses sujeitos estão atentos para a necessidade de monitoramento da linguagem que empregam nos eventos interativos de que participam, assumindo eles próprios a postura "vigilante" quanto à adequação de sua linguagem escrita. 


\section{Resultados}

O primeiro objetivo específico deste artigo visa entender as crenças dos estudantes pesquisados sobre o internetês. Para tanto, discutiremos alguns dados coletados em quatro perguntas do questionário aplicado. Ao serem questionados se a leitura de textos com internetês não ficava clara, os estudantes marcaram diferentes respostas, conforme se verifica na Figura 1:

\section{Figura 1 - Respostas à questão "A leitura de textos com internetês não fica clara"}

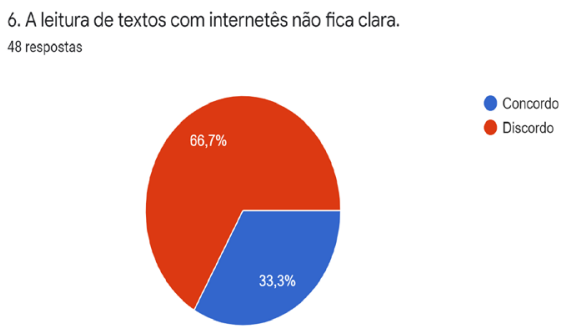

Fonte: Elaborada pelos autores.

Desse modo, podemos dizer que $16(33,3 \%)$ dos informantes concordaram com a afirmação segundo a qual "A leitura do internetês não fica clara". Em contrapartida, 32 (66,7\%) discordaram dessa crença.

A diferença de respostas a essa questão reforça mais ainda a ideia de que a clareza dos textos com internetês vai depender da pessoa com quem se está usando esse dialeto, o qual é geralmente mais usado entre adolescentes da contemporaneidade e pessoas habituadas à comunicação eletrônica informal. Sendo assim, se usarmos esse dialeto com pessoas que não estão incluídas nesses grupos, provavelmente, como elas não estão acostumadas a essa linguagem, a leitura não ficará clara. Ao contrário, se usarmos o internetês em uma conversa com outra pessoa que utiliza essa linguagem, o esperado é que não haja problemas de compreensão. Isso nos leva a entender que a facilidade ou dificuldade de leitura do internetês é algo relativo, dependente do conhecimento dos sujeitos acerca do funcionamento dessa variedade linguística, conforme discute Brito (2015).

Apesar disso, a maioria dos respondentes assumiu o posicionamento de que a leitura de textos com o dialeto escrito supramencionado fica clara. Provavelmente, isso ocorreu porque todos que responderam o questionário são adolescentes, e boa parte deles está inserida no grupo de pessoas que utilizam o internetês, por isso a maioria discordou da afirmação feita na questão.

Em relação à ideia de que "O internetês constitui um vício de linguagem a ser evitado", a maioria dos informantes concordou com essa crença, como pode ser visto na Figura 2:

Figura 2 - Respostas à questão "O internetês constitui um vício de linguagem a ser evitado"

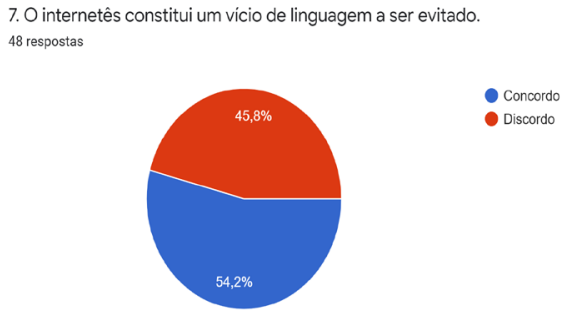


Podemos verificar que 26 estudantes $(54,2 \%)$ concordaram com tal ideia e $22(45,8 \%)$ discordaram dela. Nessa perspectiva, os dados obtidos nessa questão fazem-nos retomar o que é defendido por Brito (2015), para quem o internetês é consequência do processo de variação linguística, que é um fenômeno inerente às línguas naturais e não atrapalha o funcionamento do sistema linguístico. Em contrapartida, algumas dessas variedades são estigmatizadas, consideradas incorretas ou ruins por certa parcela conservadora da sociedade, que, preconceituosamente, associa seu uso a ideias negativas e até apocalípticas, como a crença de que o internetês vai abolir a gramática normativa, o que não passa de um equívoco rebatido por Brito (2013). Além disso, por se tratar de um dialeto escrito, essa variedade se contrapõe à forma padrão e normativa do português, apresentado, pois, estratégias e regularidades, sobretudo abreviações, entre outras subversões da escrita padrão. Essas características são utilizadas para economizar tempo no processo de comunicação em situações informais, bem como para acrescentar aspectos da oralidade e de expressões não verbais à comunicação (GONZALEZ, 2007; MOURA; PEREIRA, 2011), tornando a interação mais dinâmica e simples.

A maior parte dos estudantes que responderam à questão em análise talvez não tenha levado em conta a perspectiva supracitada, já que eles concordaram com a afirmação ora discutida. No entanto, gostaríamos de frisar que o simples uso do internetês em situações comunicativas informais não deve ser visto como um "vício". De fato, é preciso ter consciência para não empregar esse dialeto escrito em textos formais, como redações escolares ou de concursos, sob pena de o sujeito ser prejudicado caso faça isso. Portanto, a crença de que o internetês é um vício de linguagem que precisa ser evitado apresenta um caráter generalizante e pode ser rebatida cientificamente.

A Figura 3 resume as respostas dos estudantes quando questionados se o internetês está relacionado ao processo de variação linguística.

Figura 3 - Respostas à questão "O internetês reflete o processo de variação linguística"

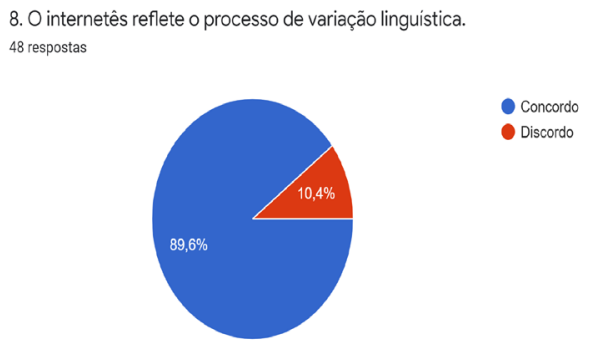

Fonte: Elaborada pelos autores.

Sendo assim, houve uma diferença significativa em relação ao posicionamento dos respondentes do questionário. 43 (89,6\%) dos estudantes assinalaram "concordo", enquanto apenas 5 $(10,4 \%)$ responderam "discordo".

Dessa maneira, o resultado obtido com esse questionamento vai ao encontro do pensamento de Brito (2015) e de Coelho et al. (2015). Para esses autores, "variedade" é uma fala ou forma de expressão característica de determinado grupo, que é influenciado por diversos fatores, sejam eles geográficos, sociais, ocupacionais ou um hábito em comum. Nessa perspectiva, o uso assíduo das redes sociais é um dos fatores que cooperou para o surgimento e utilização do internetês, o qual, por consequência, é considerado por Brito (2015) como uma variedade característica da esfera virtual da comunicação humana. Assim sendo, a maioria dos informantes apresentou, na questão em análise, um posicionamento que se adequa aos estudos linguísticos contemporâneos que buscam não ditar o que é certo ou errado, mas explicar os condicionadores linguísticos e extralinguísticos que favorecem a variação da língua.

A questão número 10 do questionário era uma pergunta aberta a qual assim se constituiu: "Você considera o internetês prejudicial à sua aprendizagem? Justifique." A partir da análise dos 
dados coletados, é possível dizer que as respostas dos informantes a essa questão podem ser divididas em três grupos, a saber: "sim", "não" e "depende". Essa divisão leva em conta não só a presença de tais palavras no início das respostas, mas também o conteúdo delas. Vale lembrar que nem todos os estudantes justificaram o que responderam. Do total de respondentes, 26 afirmaram que o internetês não prejudica sua aprendizagem. Vejamos a seguir algumas das respostas desse grupo:

(01) Não, pois mesmo que eu utilize na Internet, eu não utilizo em outros ambientes. (Cauã, 15,1 o M).

(02) Não. O internetês é simplesmente situacional, dependendo do meio de comunicação e contexto. Não vai afetar meu aprendizado, já que não o uso em contexto escolar e formal. (Pablo, 18, 2ㅇ M).

(03) Não, é isso que a língua faz, muda e se adapta com o tempo. (Sara, 19, 3o V).

(04) Não. Cada pessoa deve saber separar os momentos de uso dessa linguagem. (Gabi, 19, 4o M).

Como já dissemos, a maioria dos discentes respondeu que o internetês não prejudica a aprendizagem e as respostas acima apresentadas vêm ao encontro dos textos teóricos referenciados na revisão bibliográfica. De certo modo, as respostas de Pablo, Cauã e Gabi se relacionam, pois os três estudantes concebem o internetês dando ênfase ao contexto de uso, à situação comunicativa. Suas respostas estão em consonância com o pensamento de Bakhtin (2009, p. 37), segundo o qual a sociedade é constituída de diferentes áreas de criação ideológica e cada uma "possui seu próprio material ideológico e formula signos e símbolos que lhe são específicos e que não são aplicáveis a outros domínios". Por conseguinte, o uso adequado do internetês acontece nos textos informais da comunicação eletrônica, não devendo essa escrita ser utilizada em outras situações, como na escola ou em contextos formais. Portanto, devemos evitar o uso desse dialeto fora da internet e em momentos formais, para que assim não haja "prejuízo" na aprendizagem. É importante saber diferenciar quando e onde se deve usar ou não essa linguagem.

Na resposta 03, Sara deixa claro que a mudança e a "adaptação" linguística é algo habitual. Neste sentido, o internetês configura-se como um dialeto usado em função de uma adaptação da escrita, deixando mais prática e rápida a comunicação no meio virtual. É apenas uma variação linguística a qual não irá fazer com que a escrita oficial seja abandonada, até porque algo parecido com o internetês já ocorreu em tempos passados, consoante Ribeiro (2006). Esse autor analisou correspondências em que professores prestavam conta de como andava a aprendizagem das filhas do imperador D. Pedro I, em 1830. Sua pesquisa verificou o uso de abreviaturas emq e $q$, que correspondem, na forma oficial, a em que e que. Desse modo, podemos dizer que esse princípio de abreviação é semelhante ao que acontece no internetês. Diante disso, Brito (2015) pontua que, se as abreviaturas usadas antigamente não causaram quaisquer abandonos ou prejuízo na grafia oficial, não vai ser o uso do internetês que causará isso.

Por outro lado, 13 estudantes concordaram com o fato de que a variedade escrita aqui discutida atrapalha o aprendizado deles. Abaixo são expostas algumas respostas desse grupo:

(05) Sim, pois não é a maneira certa de escrever. (Adriel, 17, 1 V).

(06) Sim, porque é algo viciante, e como usamos nossas redes sociais todos os dias, podemos nos pegar utilizando sem ser na internet. (Glamurosa, 17, 1으).

(07) Sim, pois a normalização do uso dessa linguagem acaba prejudicando a escrita de textos formais/acadêmicos, onde tal escrita é considerada errada. (Maria, 18, 3o M).

(08) Sim, pois não praticamos a escrita correta de algumas palavras quando o utilizamos, podendo nos fazer escrever errado quando precisarmos. (Kadsuke, 18, 3o M). 
De modo geral, os discentes expõem que o uso dessa linguagem prejudica o seu aprendizado por constituir um vício linguístico. Compreende-se, então, que há uma preocupação em classificar o internetês como errado e ineficaz à comunicação escrita. Para Adriel, o internetês não é a forma correta de escrita, devendo ser evitada. Essa afirmação vai contra o pensamento de Bisognin (2009), para quem os usuários dessa variedade escrita necessitam dominar antes o português para utilizá-lo modificado na Internet. Nesse sentido, o internetês é caracterizado pela alteração na forma da palavra, mas não há mudança de significação desta. Em síntese, ocorre a criação de novas palavras, a partir das palavras já existentes na língua, não modificando seu sentido comum.

Nos excertos 06, 07 e 08, os posicionamentos de Glamurosa, Maria e Kadsuke são complementares. Eles afirmam que o internetês trata-se de algo viciante e que a normalização do seu uso acabará prejudicando a escrita formal. Contudo, é notório que o uso adequado do internetês é especificamente informal e da esfera eletrônica, pois, como já dissemos, a sociedade é formada por diferentes campos ou esferas de criação ideológica (BAKHTIN, 2009). É necessário, portanto, compreender que as diferentes situações de comunicação exigem um registro diferente da língua, adaptando-o às circunstâncias e ao contexto, pois cada cenário "possui seu próprio material ideológico e formula signos e símbolos que lhe são específicos e que não são aplicáveis a outros domínios" (BAKHTIN, 2009, p. 37).

Glamurosa e Kadsuke afirmaram, ainda, que o uso constante do internetês pode acarretar, em futuro não próximo, o esquecimento ou abandono da norma-padrão da língua portuguesa. Todavia, vale reiterar o estudo de Ribeiro (2006), o qual mostrou que a abreviação está presente na língua portuguesa há muito tempo, comprovando, assim, que o uso de formas mais estratégicas e rápidas, ao longo do tempo, não provocou o abandono da ortografia convencional. Assim sendo, "[...] não podem rejeitar a linguagem dos computadores como se ela fosse algo que transgredisse as regras da língua portuguesa, pois só conseguimos nos expressar dessa forma porque ela nos permite" (RIBEIRO, 2006, p. 98). Ressaltamos que a ausência de amostras de dados de sujeitos de 1o e 4o se dá devido ao fato de nenhum estudante dessas séries ter concordado com essa crença.

Apenas 9 estudantes apresentaram ressalvas em relação à crença de que o internetês prejudica a aprendizagem discente, destacando em suas respostas argumentos favoráveis e desfavoráveis a essa ideia. Analisemos algumas respostas desse grupo:

(09) Apenas pra quem está começando a aprender o português. Pois a maioria já é habituada à escrita normal. (Marcos, 15, 1ㅇ V).

(10) Depende, aprendemos desde pequenos as diferentes formas de falar e como usar cada uma delas, acho que devemos saber quando e onde usar cada linguagem. O internetês deve ser usado no meio da internet, com amigos ou postagens não com alguém que não o conhece e entende. (Maria, 17, 2o V).

(11) Não considero prejudicial, mas há casos que de fato atrapalha um pouco a comunicação, como a ausência de pontuação, não deixando claro a intenção daquela fala, narrativa, argumentação ou coisa do tipo. (Guilherme, 19, 3ำM).

(12) Sim e não. Às vezes é interessante poder resumir para facilitar a comunicação, mas em sentido aprendizagem, acho que é interessante usar algo próximo da norma culta. (Lavinia, 19,4 M).

Para Marcos, o internetês só prejudica aqueles que ainda estão em fase de aprendizado da língua portuguesa. Provavelmente sua resposta aponta para o fato de que os sujeitos nessa condição sedimentariam "hábitos" linguísticos que poderiam dificultar o domínio da grafia padrão.

Por sua vez, ao afirmar que "devemos saber quando e onde usar cada linguagem", Maria defende a necessidade de as pessoas monitorarem o uso da linguagem, adequando-a sempre que necessário. Desse modo, ela não estigmatiza o uso do internetês, mas chama atenção para a 
necessidade de adequação linguística, indo ao encontro do posicionamento de Coelho et al. (2015), para quem o internetês trata-se de uma variação estilística, portanto, apenas uma adaptação da linguagem para a comunicação em uma situação que não requer formalidade.

Os alunos Guilherme e Lavínia também seguem essa linha de raciocínio ao defenderem que em alguns momentos a linguagem deve se aproximar mais da norma padrão, pois a interpretação do internetês não é tão clara. Lavínia ainda acrescenta que é interessante o uso da linguagem em raros momentos, pela facilidade numa comunicação mais resumida. Suas respostas levam em conta, portanto, a preocupação com o interlocutor, que pode não compreender esse código escrito, bem como sua funcionalidade em determinados momentos, provavelmente os marcados pela informalidade.

É relevante enfatizar uma parte da resposta da aluna Maria, em que ela diz: "O internetês deve ser usado no meio da internet, com amigos ou postagens não com alguém que não o conhece e (não) entende." Entendemos que, de fato, a resposta dessa estudante dialoga com os pressupostos sociolinguísticos, segundo os quais "o papel do falante dentro de uma comunidade ou dentro de uma rede social e seu grau de exposição à mídia, entre outros, são condicionadores [sociais] que podem se mostrar significativos na análise de um fenômeno em variação" (COELHO et al., 2015, p. 45 , grifo nosso).

Desse modo, o acesso assíduo ao meio comunicativo virtual é um fator importante no emprego e recepção dessa linguagem, sendo assim poderemos supor que a dificuldade de compreensão relatada por Guilherme deve-se ao fato de ele talvez não ter uma grande exposição à comunicação virtual marcada pelo uso do internetês. Sendo assim, as pessoas podem ter um grande contato com as redes sociais e não empregarem essa variedade linguística, o que pode ser o caso desse estudante, especialmente quando ele relata a dificuldade de compreensão do internetês advinda da falta de pontuação.

De acordo com Barcelos $(2001,2006)$ e com Rocha $(2010)$, as crenças possuem uma natureza sociocultural, pois são construídas e reconstruídas através das experiências pelas quais passamos ao longo da vida. Neste sentido, depois de discutirmos as crenças de estudantes sobre o internetês, torna-se importante levar em conta o que muitos autores dessa área de estudo denominam de "possíveis origens" das crenças. Sendo assim, o segundo objetivo específico deste trabalho considera $\mathrm{o}$ aspecto sociocultural das crenças e, consequentemente, a historicidade dos informantes ao refletir sobre as diferentes vivências que contribuíram direta ou indiretamente para a formação das crenças dos estudantes pesquisados com relação à variedade linguística aqui discutida. Para atender esse objetivo, um dos itens do questionário aplicado apresentava a seguinte indagação: "Você já leu em algum lugar ou já recebeu orientação de alguém sobre o uso ou não uso do internetês? (Onde ou de quem?)".

Do total de 48 informantes, 32 responderam que nunca leram ou receberam orientação a respeito do uso ou do não uso do internetês. Esse é um dado que chama atenção, haja vista que essa escrita é tão comum nos usos linguísticos da comunicação eletrônica contemporânea, mas, ao mesmo tempo, não é objeto de discussão em tantos espaços. Isso, inclusive, pode ser visto como um dos fatores que ocasionam o emprego inadequado do uso do internetês em textos escolares formais, conforme apontado em algumas pesquisas da área (SANCHES, 2013; BRITO, 2013, 2015).

Por outro lado, 16 estudantes afirmaram já terem lido ou recebido alguma orientação envolvendo o uso do internetês. Na primeira coluna do Quadro 1, sistematizamos as experiências dos estudantes investigados, as quais podem ser vistas como fontes de suas crenças acerca do dialeto escrito (BISOGNIN, 2009; XAVIER, 2014) supracitado. Na segunda coluna, apresentamos as respostas que comprovam nossa sistematização. 
Quadro 1 - Resumo das possíveis origens das crenças dos estudantes

\begin{tabular}{|c|c|}
\hline Fonte & Resposta do estudante \\
\hline Escola & (13) Sim. Na escola. (Heitor, 18, 4 M). \\
\hline Professor & $\begin{array}{l}\text { (14) sim, alguns professores já me deram orientações } \\
\text { desse uso. (Clara, } 15,1 \text { o M). } \\
\text { (15) De um professor de redação, pois havia muitos } \\
\text { erros de ortografia por conta de abreviações comuns a } \\
\text { internet. (Heitor, 14, 1o M). } \\
\text { (16) Sim, na escola o professor de português citou. } \\
\text { (Mim, 15, 1o V). } \\
\text { (17) Sobre o não uso pela minha professora. (Eduardo, } \\
\text { 16, 1o M). } \\
\text { (18) Sim, no ambiente escolar por um professor de } \\
\text { língua portuguesa. (Maria Clara, 16, 1o M). } \\
\text { (19) Sim, na própria instituição, em aulas de língua } \\
\text { portuguesa. (Pablo Murilo, 18, } 20 \text { M). } \\
\text { (20) Já sim, professores de pt ou redação. (Marcos, 18, } \\
\text { 3o M). } \\
\text { (21) Sim, do meu ex-professor de Língua Portuguesa. } \\
\text { (Moizés, 18, 3 M). } \\
\text { (22) Sim, de uma professora no } 9^{\circ} \text { ano. (Maria Luiza, } \\
\text { 17, 3 M). } \\
\text { (23) Já. De uma professora, no ensino fundamental. } \\
\text { (Kadsuke, 18, 3o M). }\end{array}$ \\
\hline Pais & $\begin{array}{l}\text { (24) De forma gerais já tive uma conversa com meus } \\
\text { pais. (Maria Vitória, 16, 2으). }\end{array}$ \\
\hline Amigos & (25) Pelo Whatsapp, de amigos. (Adriel, 17, 1o V). \\
\hline Textos & $\begin{array}{l}\text { (26) Já vi alguns estudos sobre... A linguagem das redes } \\
\text { sociais e seus impactos na sociedade. (Michael, 30, 2o V). }\end{array}$ \\
\hline Fonte não especificada & (27) Sim. (Jnas, 18, 2o V). \\
\hline
\end{tabular}

Fonte: Elaborado pelos autores.

Por conseguinte, é possível dizer que várias são as experiências ou interações vivenciadas pelos estudantes pesquisados que, direta ou indiretamente, podem ter repercutido na forma como esses sujeitos concebem o internetês. Embora o número de estudantes que afirmaram já terem passado por alguma experiência de orientação quanto ao uso do internetês seja menor do que aqueles que responderam não terem recebido tal direcionamento, vemos no Quadro 1 um dado interessante: a discussão relacionada ao uso desse dialeto escrito esteve presente no ambiente escolar, como se verifica no excerto 13. Nas respostas 14, 17, 22 e 23, os informantes mencionaram a figura docente como responsável por mediar essa discussão. Aliás, vemos um destaque especial para os componentes curriculares de língua portuguesa e redação, pois sete estudantes mencionaram explicitamente que partiu de professores dessas disciplinas a orientação sobre os usos dessa escrita. Além disso, conversas com os pais e amigos, bem como leituras de textos também são apontadas como situações que, de alguma forma, podem influenciar as crenças dos estudantes em relação ao internetês.

\section{Considerações finais}

O surgimento de diferentes gêneros textuais no meio eletrônico favoreceu a diversidade e a variabilidade linguística, tornando-se comum o uso de uma escrita informal que diverge, em muitos aspectos, da escrita convencional e preocupa professores e estudiosos da área quando se 
trata de sua transposição para textos pertencentes a situações comunicativas formais. Pensando em investigar o que pensam os sujeitos em potencial dessa transposição inadequada, este trabalho objetivou entender as crenças de estudantes de ensino médio sobre o internetês e refletir sobre as possíveis origens dessas crenças.

Com relação ao primeiro objetivo, a análise evidenciou dados interessantes. Em relação à ideia segundo a qual textos com internetês não ficam claros, as respostas dos discentes ficaram bem divididas, mas a maioria afirmou que discorda disso. Sendo assim, defendemos que isso varia de pessoa para pessoa: a leitura não ficará clara para alguém que não tenha conhecimento desse dialeto, diferente de uma pessoa que usa frequentemente o internetês.

A maioria dos informantes concordou com a ideia de que "O internetês constitui um vício de linguagem a ser evitado". No entanto, o seu uso não deve ser visto, de modo geral, como um "vício", é preciso ter consciência para não o empregar em textos e situações formais de comunicação. Relacionado a isso, vimos também que mais de $80 \%$ dos discentes entrevistados defendem que o internetês se configura como uma variação linguística, questão que é comprovada por estudos de Brito (2015) e Coelho et al. (2015).

Quando questionados se consideravam o internetês prejudicial à aprendizagem, os estudantes pesquisados apresentaram respostas que foram divididas didaticamente em "sim", "não" e "depende". 26 informantes responderam "não", porém enfatizamos o cuidado que devemos ter quanto ao uso desse dialeto, pois é preciso diferenciar quando podemos e quando não podemos usá-lo.

Por outro lado, 13 discentes expuseram que o uso dessa linguagem prejudica o seu aprendizado, avaliando-o sob o viés da oposição "certo x errado". Contudo, é notório que o uso adequado do internetês é especificamente informal e da esfera eletrônica, sendo consequência de uma adaptação do código escrito às circunstâncias e ao contexto comunicativo. Nove (09) alunos argumentaram, ainda, que essa linguagem não ocasiona problemas no processo de aprendizagem, se utilizada na situação correta e com pessoas que estão habituados a essa forma de escrita.

No que se refere às origens das crenças discutidas, notamos que algumas experiências foram citadas pelos alunos, como leitura de textos, conversas com pais e com amigos. A maior parte dos estudantes pesquisados não recebeu instruções em sala de aula acerca do uso adequado do internetês. Já entre os que afirmaram terem recebido essa orientação, houve um destaque para a figura do professor de língua portuguesa e redação como responsável por essa mediação.

De modo geral, os estudantes apresentaram posições valorativas em consonância com os estudos sociolinguísticos, no sentido de associarem o internetês e o seu uso à perspectiva de adequação ao contexto comunicativo. Entretanto, muitos estudantes defenderam crenças que, conforme discutimos, podem ser vistas como generalizantes e passíveis de serem rebatidas a partir das pesquisas que discutem o internetês, o que evidencia a necessidade de a escola possibilitar cada vez mais espaços de debate e de conscientização sobre os usos contemporâneos da linguagem.

\section{Referências}

ÁVILA, Maribel Chagas de; COX, Maria Inês Pagliarini. O “internetês” e o legado da história da escrita. Signótica, Goiânia, v. 20, n. 2, p. 419-445, jul./dez. 2008.

BAKHTIN, Mikhail. Marxismo e filosofia da linguagem: problemas fundamentais do método sociológico na ciência da linguagem. 13. ed. São Paulo: Editora Hucitec, 2009.

BARCELOS, Ana Maria Ferreira. Metodologia de pesquisa das crenças sobre aprendizagem de línguas: estado da arte. Revista Brasileira de Linguística Aplicada, Belo Horizonte, v. 1, n. 1, p. 71-92, 2001. 
BARCELOS, Ana Maria Ferreira. Crenças sobre aprendizagens de línguas, Linguística Aplicada e ensino de línguas. Linguagem \& Ensino, Pelotas, v. 7, n. 1, p. 123-156, jan./jul. 2004.

BARCELOS, Ana Maria Ferreira. Cognição de professores e alunos: tendências recentes na pesquisa de crenças sobre ensino e aprendizagem de línguas. In: BARCELOS, Ana Maria Ferreira; ABRAHÃO, Maria Helena Vieira (org.). Crenças e ensino de línguas: foco no professor, no aluno e na formação de professores. Campinas: Pontes Editores, 2006. p. 15-42.

BISOGNIN, Tadeu Rossato. Sem medo do internetês. Porto Alegre: Editora AGE Ltda, 2009.

BRITO, Luan Talles de Araújo. Internetês e produção textual: uma análise das crenças de docentes de Língua Portuguesa. 2013. Trabalho de Conclusão de Curso (Graduação em Letras) - Departamento de Letras e Humanidades, Universidade Estadual da Paraíba, Catolé do Rocha, 2013.

BRITO, Luan Talles de Araújo. Análise das crenças de professores de língua portuguesa sobre o Internetês. 2015. Dissertação (Mestrado em Letras) - Programa de Pós-Graduação em Letras, Universidade do Estado do Rio Grande do Norte, Pau dos Ferros, 2015.

BRITO, Luan Talles de Araújo. Crenças de professores do Ensino Fundamental I sobre o dicionário escolar infantil. 2019. Tese (Doutorado em Letras) - Programa de Pós-Graduação em Letras, Universidade do Estado do Rio Grande do Norte, Pau dos Ferros, 2019.

COELHO, Izete Lehmkuhl et al. Para conhecer sociolinguística. São Paulo: Contexto, 2015.

CRYSTAL, David. A revolução da linguagem. Tradução de Ricardo Quintana. Rio de Janeiro: Jorge Zahar, 2005.

DUFVA, Hannele. Beliefs in dialogue: a bakhtinian view. In: KALAJA, Paula; BARCELOS, Ana Maria Ferreira (org.). Beliefs about SLA: new research approaches. Dordrecht: Kluwer Academic Publishers, 2003. p. 131-151.

GIL, Antônio Carlos. Como elaborar projetos de pesquisa. 4. ed. São Paulo: Atlas, 2002.

GONZALEZ, Zeli Miranda Gutierrez. Linguística de Corpus na análise do internetês. 2007. Dissertação (Mestrado em Linguística Aplicada e Estudos da Linguagem) - Pontifícia Universidade Católica de São Paulo, São Paulo, 2007.

MOURA, Mirtes Zoé da Silva; PEREIRA, Ana Paula. A produção discursiva nas salas de bate-papo: formas e características processuais. In: FREITAS, Maria Teresa de Assunção; COSTA, Sérgio Roberto (org.). Leitura e escrita de adolescentes na internet e na escola. 3. ed. Belo Horizonte: Autêntica Editora, 2011. p. 65-83.

RAMOS, Eugenio Maria de França. A circunstância e a imaginação: o ensino de ciências, a experimentação e o lúdico. 1997. Tese (Doutorado em Educação) - Faculdade de Educação, Universidade de São Paulo, São Paulo, 1997.

RIBEIRO, Tiago da Silva. Internetês: abreviatura e outras estratégias de escrita. 2006. Dissertação (Mestrado em Letras) - Programa de Pós-Graduação em Letras, Pontifícia Universidade Católica do Rio de Janeiro, Rio de Janeiro, 2006.

ROCHA, Cláudia Hilsdorf. Um estudo exploratório sobre o ensino de inglês no fundamental e foco nas crenças dos participantes. In: SILVA, Kleber Aparecido da (org.). Crenças, discursos e linguagem. Campinas: Pontes Editores, 2010. p. $227-265$.

SANCHES, Ieda Maria Nogueira. O Internetês na sala de aula: que língua é essa? 2013. Trabalho de Conclusão de Curso (Especialização em Formação de Professores com ênfase no Magistério Superior) - Instituto Federal de Educação, Ciência e Tecnologia de São Paulo, IFSP, São Paulo, 2013.

SILVA, Kleber Aparecido da. Crenças e aglomerados de crenças de alunos ingressantes em Letras (Inglês). 2005. Dissertação (Mestrado em Linguística Aplicada) - Departamento de Linguística Aplicada, Universidade Estadual de Campinas, Campinas, 2005.

SILVA, Kleber Aparecido da. Crenças sobre o ensino e aprendizagem de línguas na Linguística Aplicada: um panorama histórico dos estudos realizados no contexto brasileiro. Linguagem \& Ensino, Pelotas, v. 10, n. 1, p. 235-271, jan./jun. 2007.

SOARES, Ilma Maria Fernandes. Se der a gente brinca: crenças das professoras sobre ludicidade e atividades lúdicas. 2005. Dissertação (Mestrado em Educação) - FACED, Universidade Federal da Bahia, Salvador, 2005.

XAVIER, Antonio Carlos. A (in)sustentável leveza do internetês. Como lidar com essa realidade virtual na escola? In: ELIAS, Vanda Maria (org.). Ensino de Língua Portuguesa: oralidade, escrita, leitura. São Paulo: Contexto, 2014. p. 168-179.

Data de submissão: 31/01/2021

Data de aceite: 05/02/2021 